TP Periodica Polytechnica Civil Engineering

61(1), pp. 14-26, 2017

DOI: $10.3311 /$ PPci.9542

Creative Commons Attribution (i)

RESEARCH ARTICLE

\section{Wind Shear Stress Interpolation over Lake Surface from Routine Weather Data Considering the IBL Development}

\author{
Péter Torma ${ }^{1}$, Tamás Krámer ${ }^{1 *}$
}

Received 21-01-2014, revised 12-12-2014, accepted 12-01-2016

\begin{abstract}
In this paper a simple diagnostic wind field calculation scheme is presented which provides a spatially variable wind stress field over the lake surface for hydrodynamic modeling purposes. The goal was to develop a scheme that requires routine wind time series as input from stations located over or around the lake. The main idea is to embed an internal boundary layer model within a horizontal interpolation scheme, in this case, with inverse-distance weighting. The wind model reproduces reasonably well the increment of wind stress along the fetch due to the abrupt roughness change at the shoreline and the gradual roughening of the wavy lake surface. The proposed method is validated with wind measurements observed around Lake Balaton and through hydrodynamic modeling. Sensitivity to the parameters is analyzed, including the effect of the temporal averaging of the wind.
\end{abstract}

\section{Keywords}

wind stress, internal boundary layer, wind-induced lake hydrodynamics

\footnotetext{
${ }^{1}$ Department of Hydraulic and Water Resources Engineering, Faculty of Civil Engineering, Budapest University of Technology and Economics, H-1521 Budapest, P.O.B. 91, Hungary

${ }^{*}$ Corresponding author, e-mail: kramer.tamas@epito.bme.hu
}

\section{Introduction}

In most shallow lakes circulations, transport and mixing processes are induced mainly by the wind stress. The spatial variability of the wind stress influences strongly these motions. By studying the horizontal vorticity balance of the surface layer in Lake Kinneret and in Spremberg Reservoir, Laval et al. (2003) and Rubbert and Köngeter (2005), respectively, showed that wind stress curl is a significant source of large scale horizontal vorticity with a magnitude comparable to that of the topographical curl $[1,2]$. Considering the spatial variability of the wind forcing they achieved improvements in simulated long wave amplitudes, phases and velocity fields. The curl of the wind stress affects not only the surface-layer circulation but also the depth-averaged flow field $[3,4]$ with a maximum extension of $2.2 \mathrm{~km}$ and is situated in a dead ice hole with steep slopes on the east and west coasts. A part of the coastal area is covered with forest, creating a strong shelter from prevailing south-westerly winds. The system of shallow water equations is discretized with the modified Utnes (1990). The lack of data on the spatial variability of wind is identified as an important source of uncertainty [5].

When considering medium-sized lakes with dimensions up to several ten kilometres, the spatio-temporal variability of the wind stress may be attributed to the dynamics of weather fronts, surrounding topography, mesoscale weather phenomena (lake breeze, thunderstorms), and to internal boundary layers. Finardi et al. (1997) summarise numerical techniques to model the wind field over complex topography in this spatial range. Diagnostic models can be used to reconstruct the wind distribution from experimental data or by downscaling coarse-resolution weather model data, assuming stationary equilibrium. Prognostic models, on the other hand, describe the time evolution of the meteorological variables by solving time-dependent equations with imposed boundary conditions [6].

Whereas wind energy and pollutant dispersion studies are mainly concerned by the 3D distribution of the wind field, it is the wind stress at the lower boundary (= the water surface) that is of importance to lake hydrodynamics. The lack of data on the spatial variability of wind is actually identified as an important source of uncertainty in the modelling of lake motion [5]. 
The wind forcing imposed in a lake model can be obtained by downscaling regional weather models [7]. In the hydrodynamic forecasting model of Lake Constance, Scheuermann et al. (2008) accounted for the mesoscale impact of the surrounding topography by using a divergence-free reconstruction of the $3 \mathrm{D}$ velocity field [8]. The effect of thermally driven circulations or wind sheltering may be modelled using local wind models ranging from expensive computational fluid dynamics (CFD) simulations to simple semi-empirical diagnostic procedures.

Wind stress varies systematically in all lakes regardless of surrounding topography or wind climate. This variation is due to the development of an internal boundary layer (IBL) within the surface layer of the atmosphere. In fact, across the lakeshore there is always a sudden change in surface roughness (and often a change in temperature and moisture, too), and this gives rise to an IBL that grows streamwise on the leeside of the transition $[9,10]$. The IBL-related wind stress curl can have a major share in the horizontal vorticity balance and it alone can determine the circulation pattern in the lake [11]. The effect of the wind stress curl manifests itself in a return flow along the upstream shoreline. This circulation pattern, regularly observed in nature, cannot be replicated with a lake model unless the spatially uniform wind stress is substituted with one that accounts for the gradual increase of the stress with the distance from the upwind shoreline, as reported for Lake Neusiedl [12], Lake Belau [3] with a maximum extension of $2.2 \mathrm{~km}$ and is situated in a dead ice hole with steep slopes on the east and west coasts. A part of the coastal area is covered with forest, creating a strong shelter from prevailing south-westerly winds. The system of shallow water equations is discretized with the modified Utnes (1990) and the Spremberg reservoir [2].

In a diagnostic model aimed at reproducing wind-induced lake motion, it is customary to impose the wind stress field by first interpolating wind measurements available at a few points over and around the lake. Most of the applied methods do not incorporate the systematic modification introduced by the IBL. Laval et al. (2003) employ a bilinear scheme over Lake Kinneret [1], Beletsky et al. (2003) and Scott el at. (2004) use the natural neighbour technique on the Laurentian Great Lakes [7, 13], while Cook et al. (2002) and Rueda et al. (2009) use the multipass spatial interpolation scheme of Barnes (1964) [5, $14,15]$ the largest 'man-made' water body wholly within California, was formed in 1904 as the result of a levee failure along the Colorado River. Initially, flow into the Salton 'Sink' created a fresh water lake about $24 \mathrm{~m}$ deep with a water surface about $85 \mathrm{~m}$ below the level of the ocean. Salinity of the water body, at first roughly the same as the river, rose rapidly due to solution of previously accumulated residual salt, then following levee repair, adjusted to the combined influence of agricultural drainage accretions and evaporative losses. Water levels adjusted accordingly, at first declining then rising slowly until the mid 1930s when a level about $75 \mathrm{~m}$ below ocean level was reached. Thereafter, both water levels and salinity gradually rose, so that at present the surface elevation of the Sea stands

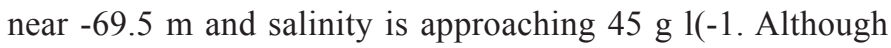
many empirical formulas exist for describing the changes of the wind profile with fetch within an IBL, few efforts (e.g. those by [5]) have been made to incorporate one of these into a horizontal interpolation scheme. In some studies where the wind stress field was made fetch-dependent, the stress field was derived from only one anemometer, thus the spatial variation of the upstream overland wind was ignored $[12,16]$. Verkaik (2001) implemented a two-layer model composed of a surface and an Ekman layer, where ground-based wind is transformed to a macro-wind on top of the Ekman layer, then this macro-wind is interpolated spatially using the Barnes method, finally the interpolated macro-wind can be transformed back to the surface at any point [17]. Although the IBL is not explicitly implemented in this model, by considering roughness footprints in the vertical transformation the IBL development is approximated quite well.

The aim of the present work is to develop a computationally efficient, semi-empirical diagnostic calculation scheme of wind stress field based on routine wind data from arbitrarily scattered anemometers, incorporating the development of an internal boundary layer. The scheme considers not only the abrupt land-to-lake roughness transition but also the gradual variation of surface roughness by the fetch over the wavy water surface. The boundary-layer model follows the same algebraic model as in the paper [11] and it is validated here against data from Lake Balaton. The wind stress distribution over the lake is obtained by an inverse-distance weighted interpolation. It will be shown by sensitivity analysis that the model cannot be calibrated unambiguously if only wind speed data are available because the wind stress field differs much depending on the choice of the calibrated parameters, in spite of an equally good fit of the wind speed at the anemometers. However, by also matching the modelled hydrodynamic response of the lake, the ambiguity could be removed from the calibration of the wind model parameters. Besides the spatial variations of wind forcing, time scale issues are also investigated through the energy spectra of water level fluctuations in order to capture accurately seiche motions of higher frequency.

The paper is organized as follows. In the next section the semi-algebraic IBL model and the wind stress field interpolation technique are described in detail. Then, in the third section the application of the wind stress model is presented for Lake Balaton. Wind model calibration and sensitivity analysis is followed by the analysis of the hydrodynamic response of the lake by means of water level fluctuations.

\section{A diagnostic wind stress model}

As it was mentioned, due to the abrupt surface roughness change at the perimeter of the open lake, an internal boundary 
layer develops within the atmospheric boundary layer. Within the IBL, the vertical wind speed profile is affected by the roughness of the water surface, while above the IBL the profile still reflects the equilibrium with the surface conditions of the upstream land (Fig. 1).

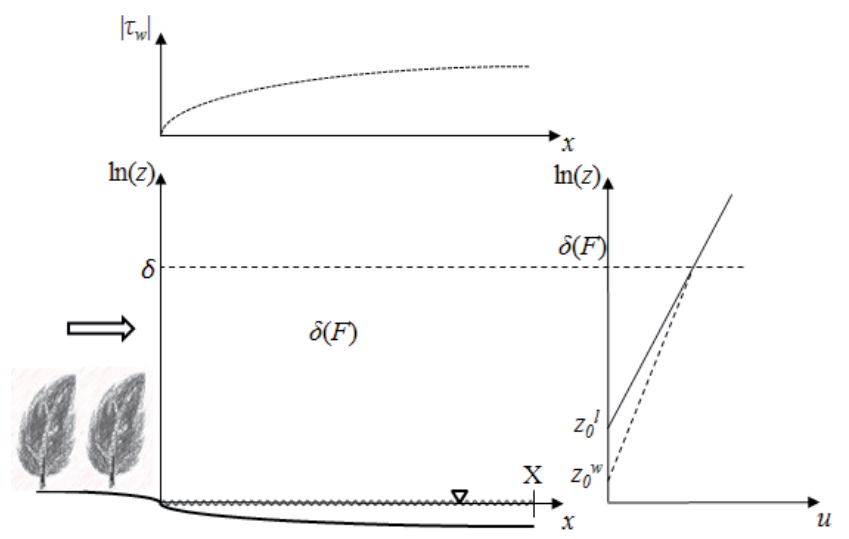

Fig. 1 Sketch of the development of an overlake internal boundary-layer (central diagram, dash-dotted line = top of the IBL), the corresponding fetchdependent profile of the wind shear stress (upper diagram) and the vertical wind speed profile at X (diagram on the right). Wind is blowing from the left. The vertical elevation axis is logarithmic.

From our point of view the main consequence is the fact that the wind stress over the water depends on fetch and influences highly the flow patterns in the lake. The semi-algebraic model suggested by Taylor and Lee (1984) and adopted e.g. by Józsa et al. (2007) to describe the vertical profile development is followed and improved in this paper $[12,18]$. The wind stress model consists of two parts. Firstly, the semi-algebraic IBL model calculates the velocity distribution in the vertical plane aligned with the wind, yielding the 1D wind stress profile along the fetch for each anemometer. The second part of the method interpolates the wind stress horizontally over the lake using inverse-distance weighting. These two steps are described in the next sections.

\subsection{IBL profile}

The effect of roughness change of the land-water transition is put into focus, therefore the current model is restricted to adiabatic conditions in the surface layer. With this restriction, a basic assumption of the procedure is that the vertical wind speed profile is logarithmic over the land and piecewise logarithmic over the water surface. Specifically, the airflow over land is in equilibrium with the surface roughness and the vertical profile can be calculated as

$$
u^{l}\left(z_{r e f}\right)=\frac{u_{*}^{l}}{\kappa} \ln \left(\frac{z_{r e f}}{z_{0}^{l}}\right),
$$

where $u$ is the wind speed at height $z_{r e f}, u_{*}$ is the friction velocity and $z_{0}$ is the aerodynamic roughness height of the land, superscript $l$ refers to land. Over the water, the velocity profile within the IBL is analogous, but with a fetch-dependent roughness:

$$
u^{w}(z, x)=\frac{u_{*}^{w}(x)}{\kappa} \ln \left(\frac{z}{z_{0}^{w}}\right),
$$

where $x$ is the distance along the fetch and superscript $w$ refers to water. The variable roughness height of the water surface, $z_{0}^{w}$, is determined according to the commonly used Charnock's relation [19]:

$$
z_{0}^{w}=\alpha \frac{u_{*}^{w 2}}{g}
$$

where $\alpha$ is a parameter that can be related to the wave age [20]. In our model $\alpha$ is a constant to be calibrated.

Above the IBL (at heights greater than $\delta$ ), the upstream overland profile prevails. There is no step change in $u$ at the top of the IBL (see Fig. 1), that is,

$$
u^{w}(\delta, x) \cong u^{l}(\delta)
$$

Many formulae exist for IBL height development in adiabatic conditions. A detailed review is given by e.g. [21] The commonly used simple formula by Elliott [22] was successfully validated against numerical simulations for situations similar to ours [12]. According to this, the height of the boundary layer is

$$
\delta(x)=(0.75-0.03 \cdot M)\left(\frac{x}{z_{0}^{w}}\right)^{0.8} \cdot z_{0}^{w},
$$

where $M$ is the ratio of the logarithms of the roughness lengths:

$$
M=\ln \left(\frac{z_{0}^{w}}{z_{0}^{l}}\right)=\ln \left(z_{0}^{w}\right)-\ln \left(z_{0}^{l}\right) .
$$

Substituting (1) and (2) into (3) yields:

$$
u_{*}^{w}(x)=u_{*}^{l} \cdot \frac{\ln \left(\frac{\delta(x)}{z_{0}^{l}}\right)}{\ln \left(\frac{\delta(x)}{z_{0}^{w}}\right)}
$$

where the friction velocity over land can be calculated by rearranging (1):

$$
u_{*}^{l}=\frac{\kappa \cdot u^{l}\left(z_{r e f}\right)}{\ln \left(\frac{z_{r e f}}{z_{0}^{l}}\right)} .
$$

In this approach two parameters have to be determined: $z_{0}^{l}$ and $z_{0}{ }^{w}$, the latter not directly but through Charnock's $\alpha$. This can be done directly by means of high-frequency turbulence measurements (using e.g. the eddy-covariance technique), since

$$
\tau=-\rho_{a} \cdot \overline{u^{\prime} w^{\prime}}=-\rho_{a} \cdot u_{*},
$$

where $\tau$ is the wind stress, $\left(\overline{u^{\prime} w^{\prime}}\right)$ is the Reynolds average of the product of horizontal and vertical velocity fluctuations around the mean, and $\rho_{a}$ is the density of the air. However, 
routine meteorological observations typically include only wind averages with a time resolution of 5 minutes to 1 hour.

The system of Eqs. (3), (5) and (7) can be solved iteratively for the profile of if the wind speed is given at any height over the land or even over the lake along that section.

\subsection{Spatial interpolation of the wind stress field}

The IBL model described above will reconstruct the instantaneous wind stress profile along a wind oriented line passing through an anemometer, in such a way that the wind speed matches at the anemometer. Then, by assuming that the overland wind vector is uniform along the upstream lakeshore, it becomes possible to extrapolate the wind speed (and hence the wind stress) from a single anemometer to any point over the lake. The further we are from the anemometer, the more uncertain is the extrapolated wind, owing to the mesoscale variability of a real wind field. Another source of error increasing with distance is that the IBL model assumes at all instants that a quasi-steady wind field will have developed over the whole lake, whereas air waves propagate at finite speeds and the atmospheric boundary layer is rarely at equilibrium.

To resolve mesoscale variability, wind data should be available at several representative locations near the lake or over it. Usually the wind vector extrapolated using the IBL model from one anemometer to another one will not match the wind vector measured at the latter. A clear manifestation of this is that the IBL model does not describe changes in the wind direction. Verkaik (2001) derives the surface wind field from wind stations over the Netherlands by performing the Barnes interpolation on the macro-wind (= geostrophic wind) in such a way that roughness changes are taken into account using a land use map and upstream footprints [17].

Here a somewhat similar but simpler spatial interpolation scheme is proposed. It captures the IBL developing over water but ignores any IBL that forms over land, assuming that their influence on the wind stress input of the lake model is secondary. The scheme can be summarised as follows: extrapolate the wind stress vector field from each anemometer over the whole lake using the IBL algorithm described in Section 2.1, then combine the fields associated with each anemometer with an inverse distance weighting (IDW) to obtain the resulting wind stress vector field. Figure 2 sketches the algorithm for an arbitrary point, which is typically a node of the computational mesh where the wind stress needs to be discretised.

In an arbitrary point $i$ the instantaneous wind stress vector $\left(\boldsymbol{\tau}_{i}\right)$ is the weighted average of stresses arising from every single station at the same time (Fig. 2):

$$
\tau_{i}=\sum_{j=1}^{N} \frac{w_{i j} \cdot \tau_{i j}}{\sum_{j=1}^{N} w_{i j}},
$$

where $\boldsymbol{\tau}_{i j}$ is the wind stress vector at point $i$ extrapolated from anemometer $j$ and $w_{i j}$ is the weight of anemometer $j$ for point $i, N$ is the number of anemometers. The non-normalised weight of an anemometer is a function of its inverse distance from the point:

$$
w_{i j}=\frac{1}{d\left(\mathbf{x}_{i}, \mathbf{x}_{j}\right)^{p}},
$$

where $p$ is a power parameter, $\mathbf{x}_{i}$ and $\mathbf{x}_{j}$ are the horizontal positions for point $i$ and anemometer $j$, respectively and function $d$ is the Euclidean distance.

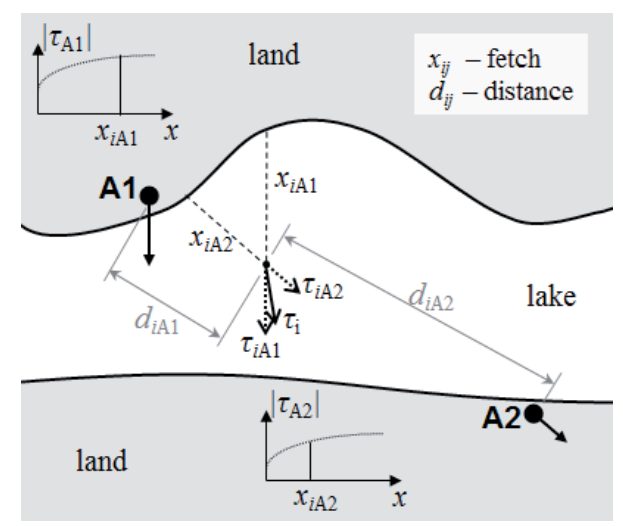

Fig. 2 Sketch of wind stress interpolation to an arbitrary point (indexed $\boldsymbol{i}$ ) from two onshore anemometers (A1 and A2). The vectors show the wind measured at A1 and A2, as well as the composition of the resultant wind stress vector at point $\boldsymbol{i}$.

\subsection{Parameter selection}

The wind forcing calculation scheme possesses three free parameters, namely the roughness lengths of land $\left(z_{0}^{l}\right)$ and water (through Charnock $\alpha$ ), and the power parameter $p$ of the IDW interpolation. These parameters can be determined by minimising the residuals between modelled and measured winds if data is available at different fetches at the same time. The roughness parameters are related to the physical environment, whereas $p$ depends on the configuration of the anemometer network.

Józsa et al. [12] calibrated only $z_{0}^{l}$, while the value of $\alpha=$ 0.0185 was fixed following recommendations in the literature. By analysing the sensitivity to changing $\alpha$ and $z_{0}^{l}$ simultaneously, we found that wind speed acceleration over the lake can be almost identical for different parameter combinations. For instance, Fig. 3 shows that the IBL wind speed profile along the fetch is almost identical for two strikingly different combinations of $\alpha$ and $z_{0}{ }^{l}$. In case $A$, the combination is $\alpha=0.073$ and $z_{0}{ }^{l}=0.6 \mathrm{~m}$, while in case $\mathrm{B}, \alpha=0.0185$ and $z_{0}{ }^{l}=0.5 \mathrm{~m}$. Both combinations are realistic so it is not clear which one to adopt. To illustrate the difference between these two cases we calculate index $M$ to measure the ratio of land and water roughness as given by Eq. (6). At a fetch of $10000 \mathrm{~m}$, when the new equilibrium is almost reached, $M_{A}=-4.7$ and $M_{B}=-6.29$ 

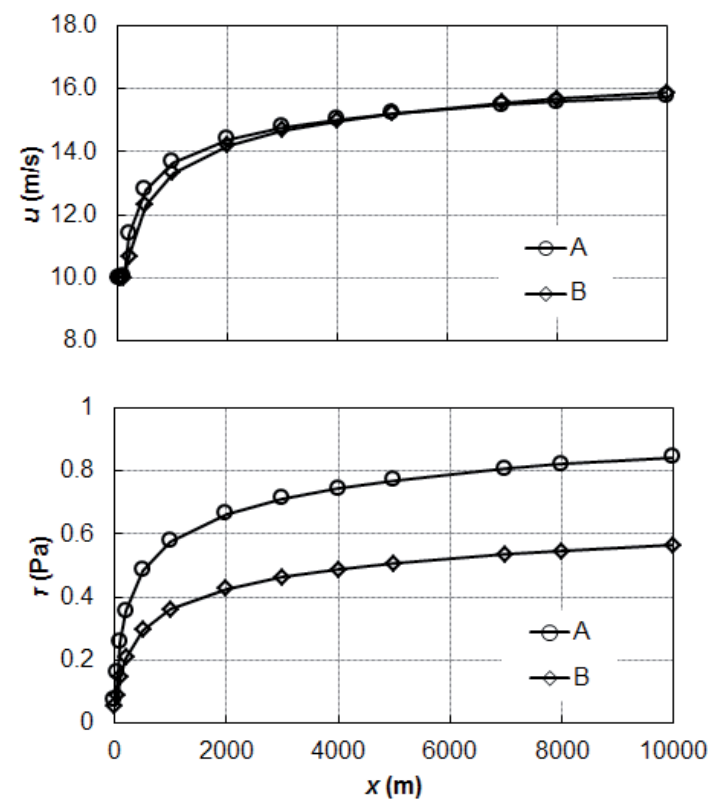

Fig. 3 Longitudinal profile of wind speed at $10 \mathrm{~m}$ (upper) and wind stress (lower) over lake surface. Case A: $\alpha=0.073$ and $z_{0}^{l}=0.6 \mathrm{~m}$ (circles), Case B: $\alpha=0.0185$ and $z_{0}^{l}=0.5 \mathrm{~m}$ (diamonds).

Unexpectedly, the longitudinal wind stress profile over the water surface differs significantly for these two cases. When surfaces are rougher (case A) the wind force transmitted to the lake is also greater by a factor of 1.5 at $10000 \mathrm{~m}$ leeward. Consequently, the algebraic IBL model cannot be properly calibrated based on wind data only even if these are measured simultaneously at various fetches.

In order to appropriately find the right combination of the IBL parameters that produces an accurate wind stress field, one solution is to measure turbulent momentum fluxes at least in one point. However, turbulent fluctuation measurements are not part of regular weather observations, so they need to be acquired in a targeted campaign.

To be consistent with the general goals of this work, we sought other means to calibrate the wind stress model, using routinely measured data exclusively. To achieve this, we have involved the hydrodynamic model of the lake into the calibration procedure. Indeed, an additional calibration criterion is gained by fitting the modelled amplitude of the lake surface motion at recording gauges, through which the wind energy input into the lake, hence the integral of the wind shear stress is ensured and the calibration problem becomes well posed.

Until now we dealt with the selection of the roughness parameters, but the shear stress distribution along the wind direction is also sensitive to the power parameter $p$ of the IDW interpolation. By taking $p=0$, weights of the interpolation become equal for all anemometers and the resulting stress field is a simple arithmetic mean of the stress fields determined from each anemometer. In this case local small-scale features of the mesoscale wind distribution will vanish. By increasing $p$, the wind stress vector at an arbitrary point becomes more determined by the closest anemometers, as would be expected from a realistic field. However, there is an upper limit to $p$, as a larger value can produce unrealistically abrupt changes around the anemometers in the interpolated field. This known drawback of the IDW interpolation is the so-called "bull's eye effect".

The parameter sensitivity and the accuracy of the proposed IBL-based wind stress interpolation scheme is explored for Lake Balaton in the remaining part of this paper.

\section{Application to Lake Balaton}

The wind stress interpolation scheme presented in this paper targets applications where wind data is available from a limited number of anemometers distributed around and over the lake. While a dedicated dense wind monitoring network can be set up to provide detailed data to real-time lake models or to hydrometeorological field surveys, it is clearly beneficial to improve the interpretation of historical time series measured at weather stations around the world. The proposed scheme will be demonstrated using the case study of Lake Balaton where a sufficiently dense observation network is operated.

\subsection{Study site and hydrometeorological data}

Lake Balaton is the largest freshwater lake in Central Europe. Shores are mainly built-up. Beyond its cultural and touristic significance it has an important ecological value. The mean depth is about $3.5 \mathrm{~m}$, whereas its surface area is approximately $600 \mathrm{~km}^{2}$. The longitudinal axis of the lake is oriented E-NE and its elongated shape is divided into two main sub-basins by the Tihany peninsula. The prevailing wind direction is NNW.

Around the lake, 6-8 anemometers have been operated by the Hungarian National Directorate General for Disaster Management in the framework of the Lake Balaton Storm Warning System since 2008. The instruments are located in ports and on beaches (Fig. 4), their height above the ground ranges between 10 and $21 \mathrm{~m}$. Recorded data include 5-minute average wind speed and direction. Two weather stations (denoted A7, A8) are also operated in the middle of bay I and bay IV during the summer season. These cannot be considered "routine" weather data, however, they are used here to validate our wind forcing model. Instantaneous water levels are also available from four gauges at every 10 minutes. Figure 4 shows the different monitoring stations with collected type of data and the bathymetry of the lake.

For this study, four typical periods have been chosen when NNW winds were blowing for hours causing significant water level fluctuations. These periods spanned between 24 to 80 hours in Aug. 2008, Mar. and Oct. 2009, Jun. 2010.

\subsection{Calibration of the IBL parameters}

Stations A2 and A5 are lying almost on a line along the dominant NNW wind direction and so their data can be used to study the IBL development over Lake Balaton with little 


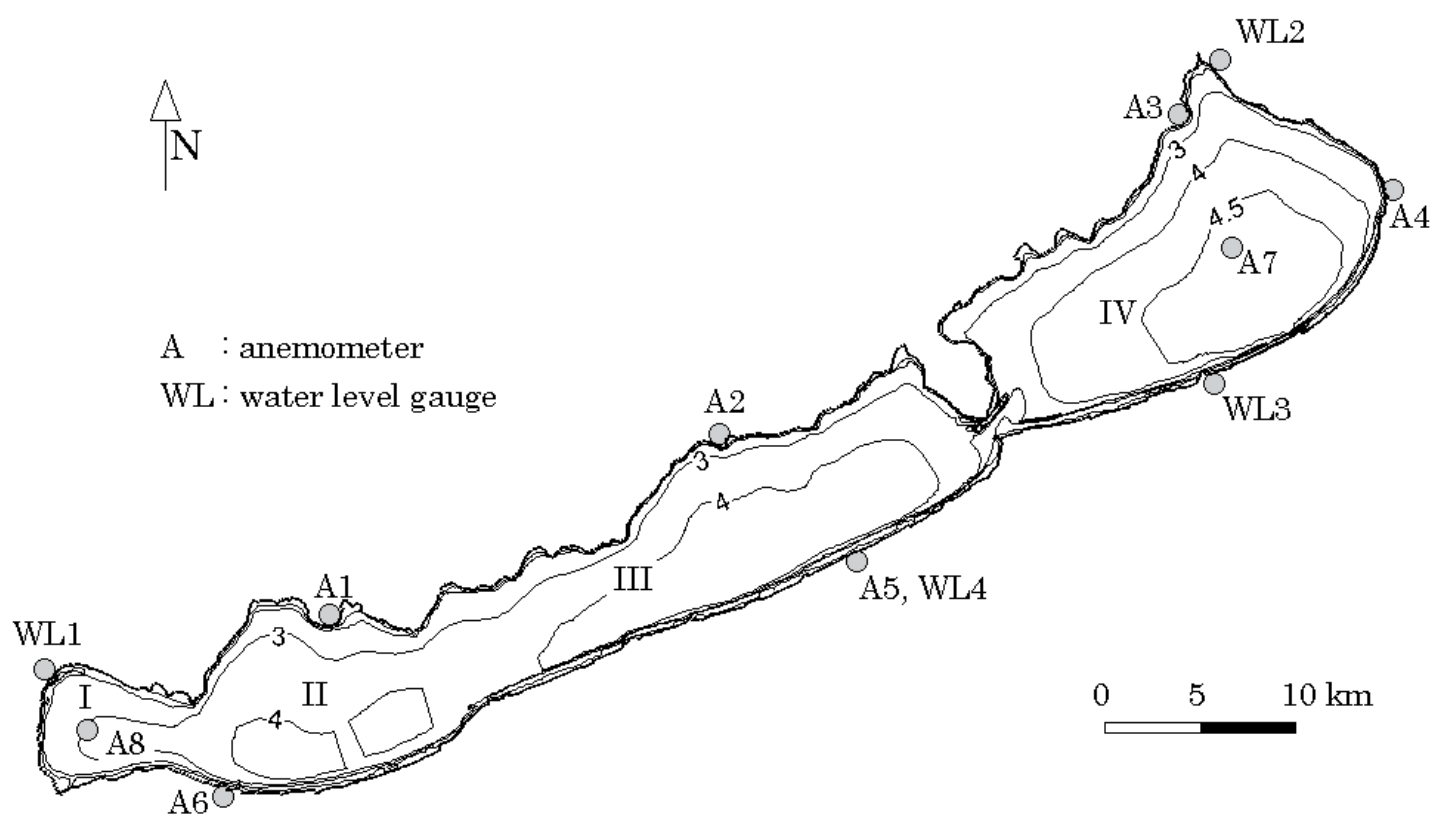

Fig. 4 Lake Balaton: depth contours in meters with respect to the mean water surface level; location of the anemometers (A) and water level gauges (WL)

sensitivity to the IDW interpolation parameter $p$. Anemometer A5 lies on the shore close to the shoreline, so that its footprint is still in the lake. For this analysis the wind vectors were first averaged to 30 minutes, and only those instants were kept when none of the averages deviated by more than $15^{\circ}$ from the orientation of the line connecting the two stations, $326^{\circ}$. That resulted in 247 simultaneous wind speeds on the two opposite shores of the lake from the four selected periods (Fig. 5). Data is quite scattered and the variance of the point cloud increases proportionally to the wind speed. This variance is higher than that encountered at another lake of similar size, Lake Fertö [11]. The higher variance is probably due to the more pronounced orographic effect of the upstream highlands and the more diverse aerodynamic roughness around the lake in contrast to Lake Fertö, which is surrounded by a fewkilometre-wide homogeneous reed belt [23]. Nevertheless, the acceleration of the wind speed over the water surface emerges clearly on the plot.

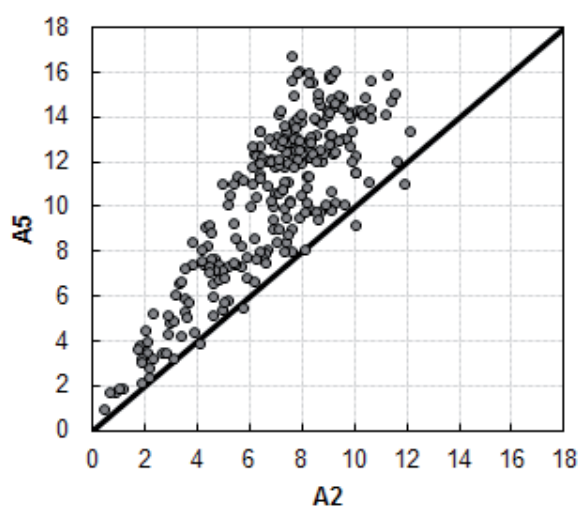

As it was described in Section 2.3 there are multiple parameter combinations that yield the same best fit to the wind speed even when concurrent data from numerous anemometers is available. It is expected that the surface roughness does not vary as much from one lake to another than that of the surrounding land, so the Charnock parameter was fixed to $\alpha=0.073$ following the findings of Vickers and Mahrt (1997) for shallow waters with limited fetch [16]. It is therefore the roughness height of the land that was calibrated, yielding $z_{0}^{l}=0.6 \mathrm{~m}$. This value is in accordance with that recommended by the Davenport classification for "rough" or "very rough" terrain [24]. With this combination, the IBL model can capture the acceleration of the NNW winds and a fairly good agreement is reached between the measured and estimated wind speeds on the leeward shore (Fig. 5). As it was described in Section 2.3 several parameter combinations can lead to a similar wind profile. As an additional criterion, the applied roughness parameters will be validated in Section 3.4 by means of the hydrodynamic response of the lake.

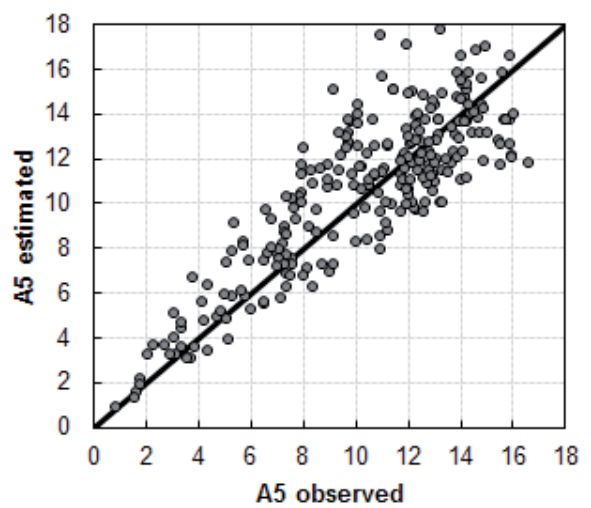

Fig. 5 Simultaneously measured wind speed on windward and leeward shore (left) and wind speeds estimated by the IBL model against measured ones (right) on leeward shore. 


\subsection{Interpolation parameter}

In order to determine an optimal value of the power parameter $p$ we conducted a cross-validation with the Lake Balaton dataset. By eliminating an anemometer from the interpolation there is an opportunity to directly compare the time series of the wind vector interpolated from the remaining anemometers against the observations. We tested the accuracy of our interpolation method and the sensitivity to the power parameter by means of anemometers A2, A5, A7 and A8. In the case of the westernmost anemometer $\mathrm{A} 8$, the extrapolation ability of the scheme is examined as A8 is well outside the convex hull of the remaining anemometers.

The calculated RMS errors of the wind speed for the period of October 2009 are shown in Table 1. Regarding the wind speed at anemometer A8, the higher the value of $p$, the smaller is the error. It shows that there is a significant difference in the wind vector at different parts of the lake and a simple averaging of the other stations is not a good approximation for the west bay. In case of anemometer A5 the accuracy of the estimation is insensitive to $p$. The velocities are somewhat underestimated because the closest anemometer is A2 and lower offshore wind speeds were observed there. In contrast, in case of anemometer A2 the wind velocities are overestimated because anemometer A5 measured accelerated onshore wind. The application of lower value of $p$ decreases the effect of local features at anemometer A5. In case of the anemometer A7 located in the middle of the east bay, the errors are contradictory hence with larger coefficients the estimated directions improve by $10^{\circ}$, while the error of velocity magnitudes increases by more than $30 \%$. Based on these results, in case of Lake Balaton using 6 onshore wind stations, a recommended value for the power coefficient is between 0.5 and 1.0 .

Table 1 RMS error of the estimated wind velocity magnitudes $(\boldsymbol{u})$ and directions $(\boldsymbol{d})$ for the period of October 2009.

\begin{tabular}{llllll}
\hline & $\boldsymbol{p}(-)$ & 0.0 & 0.5 & 1.0 & 2.0 \\
\hline $\mathrm{A} 2$ & $u(\mathrm{~m} / \mathrm{s})$ & 2.49 & 2.71 & 3.03 & 3.70 \\
& $d\left(^{\circ}\right)$ & 13.9 & 15.1 & 17.4 & 23.1 \\
\hline \multirow{4}{*}{$\mathbf{A 5}$} & $u(\mathrm{~m} / \mathrm{s})$ & 2.44 & 2.33 & 2.26 & 2.29 \\
& $d\left(^{\circ}\right)$ & 19.6 & 19.7 & 20.0 & 21.1 \\
\hline \multirow{4}{*}{$\mathbf{A} 7$} & $u(\mathrm{~m} / \mathrm{s})$ & 2.45 & 2.56 & 2.79 & 3.25 \\
& $d\left(^{\circ}\right)$ & 32.5 & 28.7 & 25.6 & 22.3 \\
$\mathbf{A 8}$ & $u(\mathrm{~m} / \mathrm{s})$ & 1.84 & 1.67 & 1.49 & 1.33 \\
& $d\left(^{\circ}\right)$ & 31.6 & 30.7 & 30.1 & 30.7 \\
\hline
\end{tabular}

It is observed that the greater the power parameter, the faster does the wind stress grow with fetch (Fig. 6) and consequently the stronger is the wind stress curl acting on the lake surface.

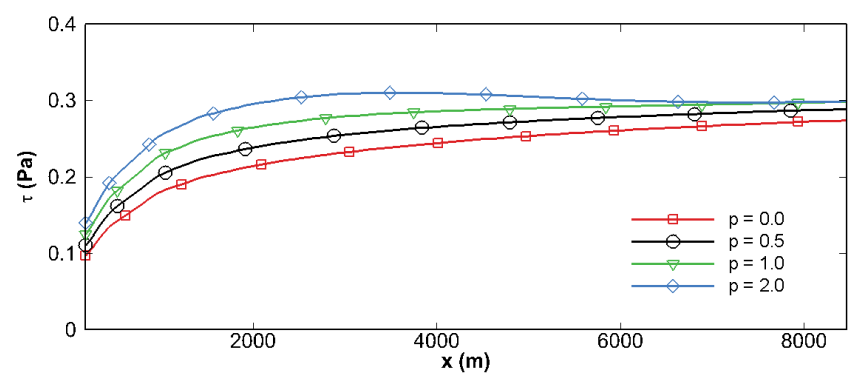

Fig. 6 Time averaged wind stress distribution along the fetch over bay III of Lake Balaton, using different values for the power parameter $\boldsymbol{p}$ of the IDW interpolation, for the period in March 2009.

The distribution of the time-averaged interpolated wind stress above the lake surface (Fig. 7) differs, confirming that the interpolation parameter has a remarkable effect not only the integral but also on the curl of the wind input of the lake model.

Furthermore, this analysis point out to those parts of the lake which are sensitive to the wind stress distribution changes. According to Table 1, and the visual evaluation of the wind stress fields (Fig. 7), the adopted power parameter is $p=0.5$. Higher values result in larger RMS errors for stations A2 and A7, and in addition to the already mentioned bull's eye effect turns up (noticeable at A6).

\subsection{Hydrodynamic response of the lake}

The ultimate purpose of our work is to improve the calculation of wind input in hydrodynamic lake models. As it was shown, several roughness parameter combinations can yield interpolated IBL-aware wind fields that fit measured wind speeds equally well, while they produce significantly different wind stress distributions. Hence, it is essential to calibrate the wind interpolation scheme by additionally requiring a good agreement in the induced lake response. This is a well posed optimisation problem when the total wind force transmitted to the lake and the induced water motions are sensitive to the parameters of the wind model. From all possible hydrodynamic variables, it is typically the water stage that has been recorded with sufficiently high resolution for years or decades, so that data is readily available for calibration at numerous important lakes in the world. As a result, the motion of the lake can usually be evaluated through the fluctuations of the lake surface at the gauges, without requiring costly measurement campaigns dedicated to the modelling. However, it is necessary that the recording interval of the water stage is short enough to capture seiches, which can be realistically expected from current lake monitoring stations. This is indeed the case for Lake Balaton that has currently nine gauges with 15 -minute resolution, from which Fig. 4 shows those that were used in this paper.

Numerical simulations of lake hydrodynamics were performed with FVCOM version 2.7 (Finite Volume Coastal 


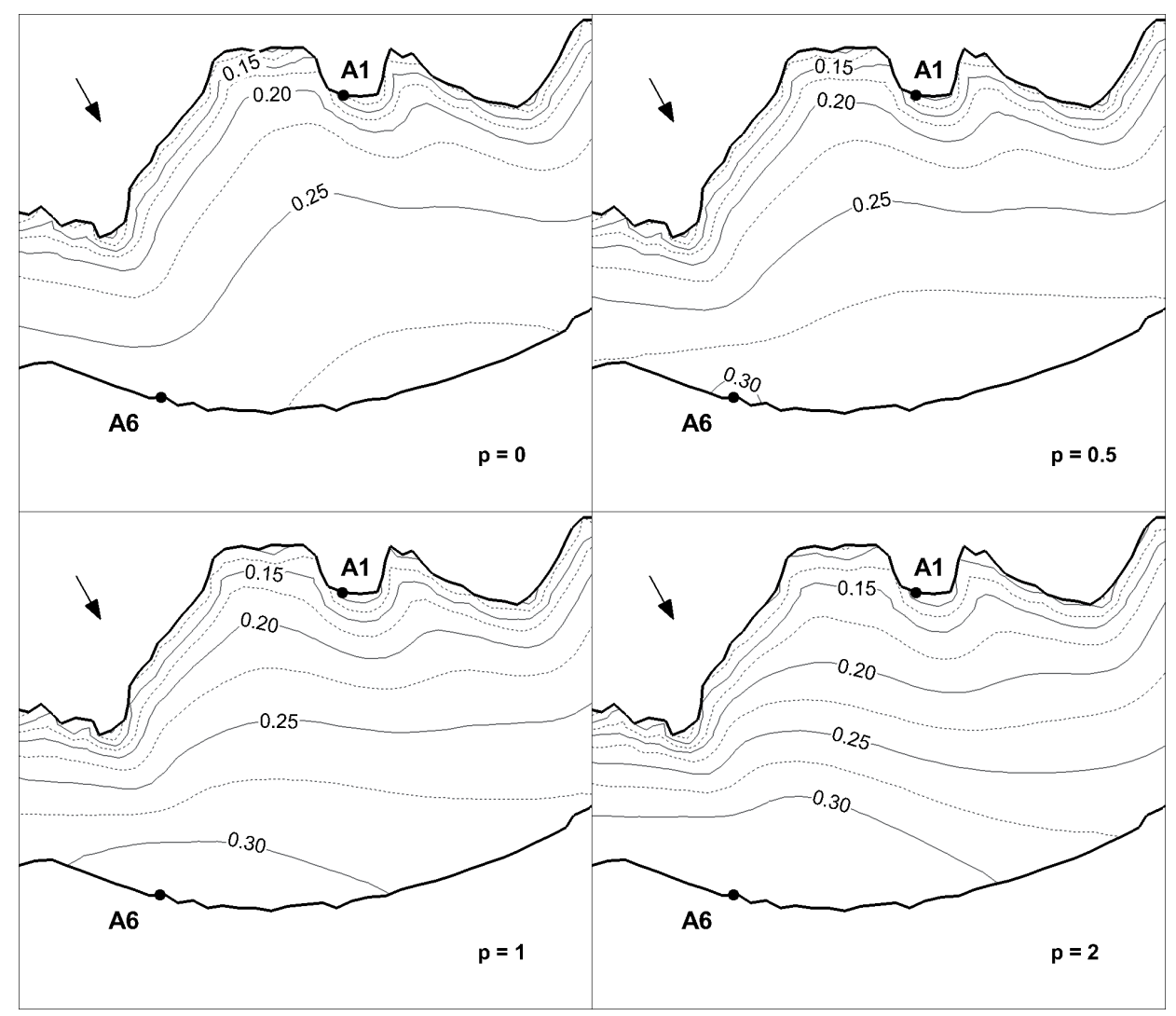

Fig. 7 Contours of the time-averaged wind stress over bay II of Lake Balaton, using different values for the power parameter $\boldsymbol{p}$ of the IDW interpolation, for the period in March 2009.

Ocean Model) [25] finite-volume, three-dimensional (3D. It is a three-dimensional primitive-equation circulation model for surface waters which uses the so-called "mode-splitting" method: the displacement of the free surface is calculated by vertically integrated equations (external mode), then the $3 \mathrm{D}$ flow field is computed under that given free surface (internal mode). The Reynolds-averaged governing equations are closed and the turbulent eddy viscosities are determined with the modified Mellor and Yamada level-2.5 and the Smagorinsky turbulence schemes for vertical and horizontal mixing, respectively. The computational domain is covered horizontally with unstructured triangular faces. In the vertical direction FVCOM uses the standard bathymetry-following $\sigma$-coordinate transformation providing accurate fitting to irregular bed geometries. Concerning the numerical solution a finite volume scheme is applied: a second-order accurate upwind scheme is used for the advective terms and a modified fourth-order Runge-Kutta scheme for time integration. FVCOM has been thoroughly verified against analytical solutions [26] the hydraulic jump, and the three-dimensional barotropic wind-driven basin. These test cases examine the properties of numerical dispersion and damping, the performance of the nonlinear advection scheme for supercritical flow conditions, and the accuracy of the implicit vertical viscosity scheme in barotropic settings, respectively. It is demonstrated that FVCOM provides overall a second-order spatial accuracy for the vertically averaged equations (i.e., external mode and validated with case studies [27, 28].

A model with a moderate mesh resolution is sufficient to reproduce water level fluctuations recorded at 15-minute intervals. The computational mesh consists of six $\sigma$ layers evenly distributed in the vertical direction with an average horizontal resolution of $400 \mathrm{~m}$. Wind forcing is imposed as a variable wind stress at cell centers. The instantaneous wind stress fields are interpolated at the time levels of wind data. In the time gap, the two nearest fields are interpolated linearly in time. Initially, velocities are set to zero and the water level to the mean of the actually observed levels over the simulated period. Simulations are run assuming a barotropic flow field.

The roughness parameters of the wind stress interpolation were determined iteratively based on wind and water level data from October 2009, measured by the regular meteorological stations and gauges. As an example, the feather plot in Fig. 8 shows a 92-hour period with a sustained, 60-hour NNW storm recorded at station A5 near the centre of the southern shore.

The hydrodynamic model and the wind stress field were validated with water level fluctuations observed at four telemetered gauges located around the lakeshore (denoted by WL1 to WL 4 in Fig. 4).

The time series of the simulated and observed water surface excursion are presented in Fig. 9 for the same 92-hour 


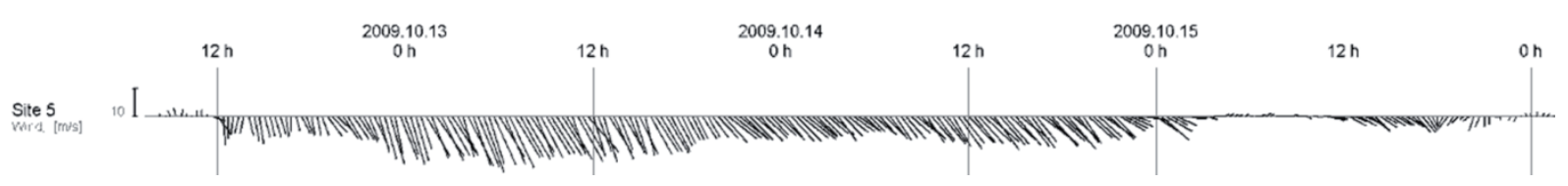

Fig. 8 Feather plot of 10-min average wind vectors measured at station A5 from 10/12/2009 0800 - 10/16/2009 0400 UTC.
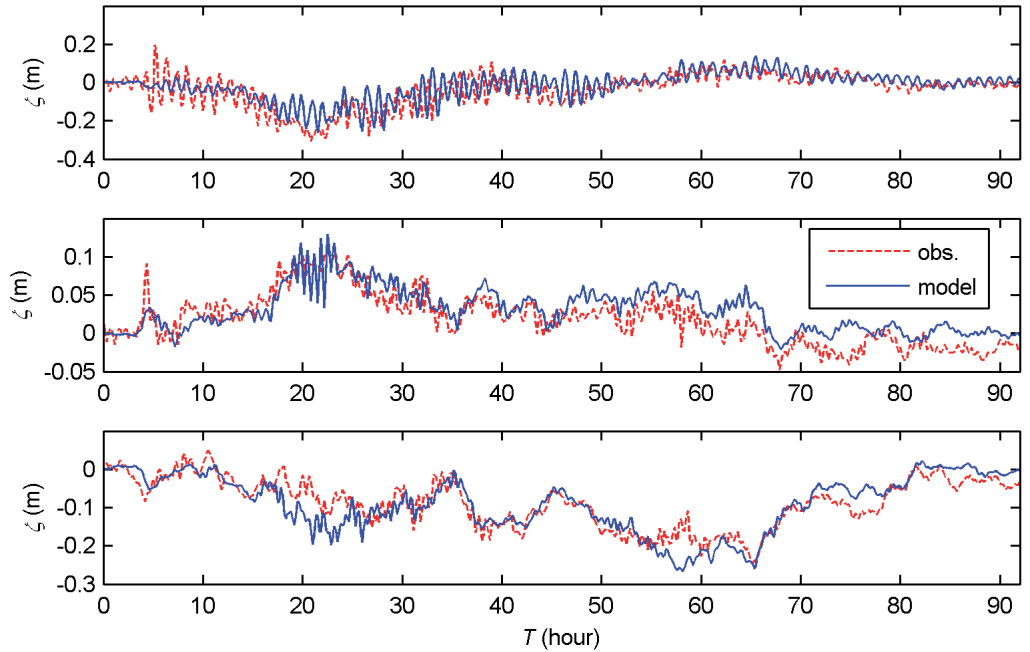

Fig. 9 Water surface excursion at gauges WL2, WL4 and WL1, respectively in the period 10/12/2009 0800 - 10/16/2009 0400 UTC

period. The modelled water levels are in fairly good agreement with observations, showing that the calculated wind energy transferred to slower lake modes (=surface setup) is estimated accurately. The best fit was achieved with the land and water roughness parameter combination $z_{0}^{l}=0.6$ and $\alpha=0.073$, respectively. Setting Charnock's parameter to lower values led to underestimated amplitudes in all cases, confirming that the lake model is a sensitive indicator of how well the wind model is calibrated.

In order to validate the wind stress interpolation and the hydrodynamic model, three other periods were simulated with unchanged wind model parameters. To stay brief, only results of the second period are presented. The wind was across the lake, the highest speeds reached $20 \mathrm{~m} / \mathrm{s}$ on the leeward shore (Fig. 10).

The model simulates correctly not only the amplitudes but also the phases of the water surface excursion (Fig. 11).

Besides the spatial interpolation, the temporal resolution of wind forcing is also investigated. Routine weather measurement data, including average wind speed and direction, are typicaly stored at regular time intervals of 5 minutes or coarser. As Józsa et al. (2000) found through numerical studies [29], the kinetic energy of wind fluctuations shorter than the averaging interval are lost in the modelled lake response. To explore the effect of time resolution, simulations are performed with a temporal vector averaging of wind data with an interval of 10 , 20 and 30 minutes. Spatially distributed wind stress fields were calculated with the described interpolation scheme based on the coarser averaged values (and interpolated linearly in time between the instants).
Seiche appears clearly in Fig. 9 and Fig. 11. Next, the influence of wind input averaging is examined through energy spectra calculated from detrended water surface excursion time series. For gauge WL2, the energy spectra of water levels with various wind averaging intervals are shown on Fig. 12 From the frequency-weighted spectral density on a logarithmic horizontal axis, it can be seen from the area under the curves that the crosswise seiche modes with a period of about $60-70$ minutes contain most of the energy. Notice that this spectrum cannot capture much shorter wind waves with a period of a few seconds, which would appear far more energetic than seiche. In case of the simulated period of October 2009 the energy peak is estimated accurately if a 10-minute temporal averaging is applied. However, using the same 10-minute averaging interval for March 2009, the amplitude of the simulated water level fluctuations is overestimated. According to the spectra of the two periods, an overall applicable wind averaging interval is approximately 20 minutes.

Water level excursion energy spectra at other stations are shown in Fig. 13 for the period of October 2009. At gauge WL4 the energy content is highly overestimated using 10-minute and underestimated using 20-minute wind averaging, whereas at gauge WL3 there is no significant difference between the effect of the two averaging intervals. Extending the averaging interval smooths out wind gusts from the spatial interpolation but removes detail and energy. Including the spectra from the other water level gauges around the lake (not presented in this paper), 20 minutes can be recommended as the overall best interval of temporal averaging on Lake Balaton, though not universally good. 


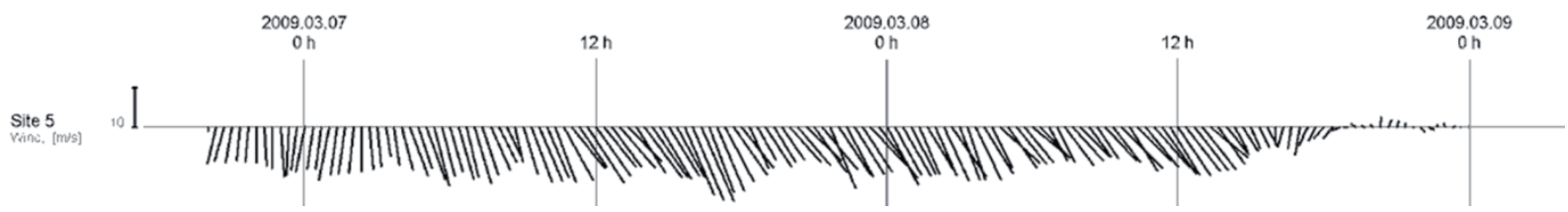

Fig. 10 Feather plot of 10-min average wind vectors measured at station A5 from 03/06/2009 2000 - 03/09/2009 0000 UTC.
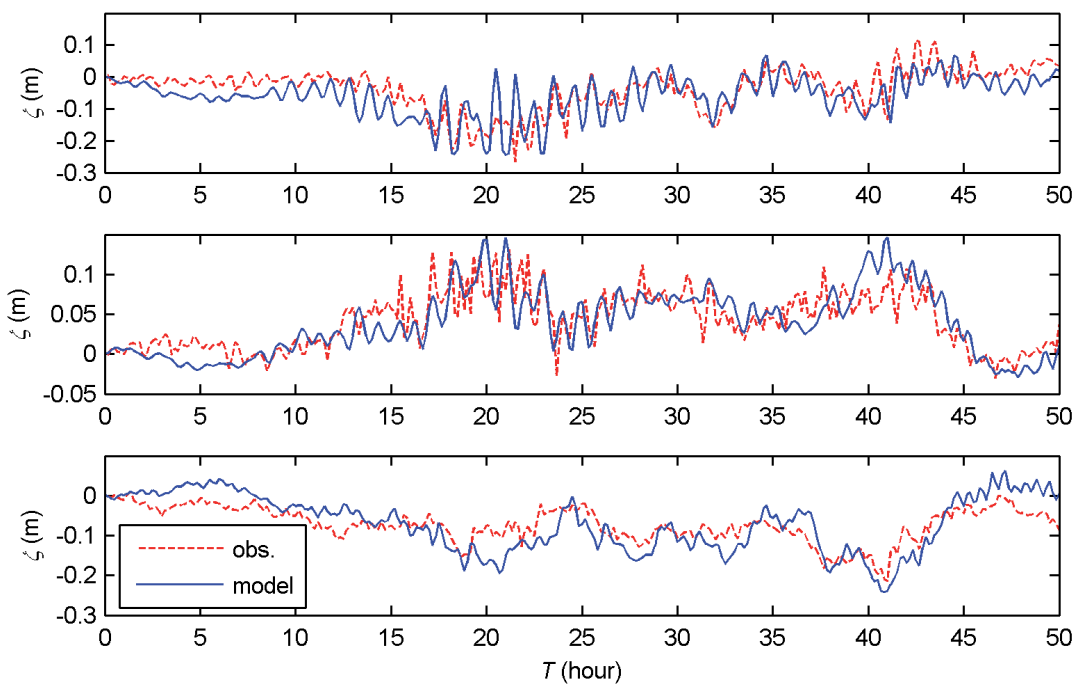

Fig. 11 Water surface excursion at gauges WL2, WL3 and WL1, respectively during the simulated period 03/06/2009 2000 - 03/08/2009 2200 UTC
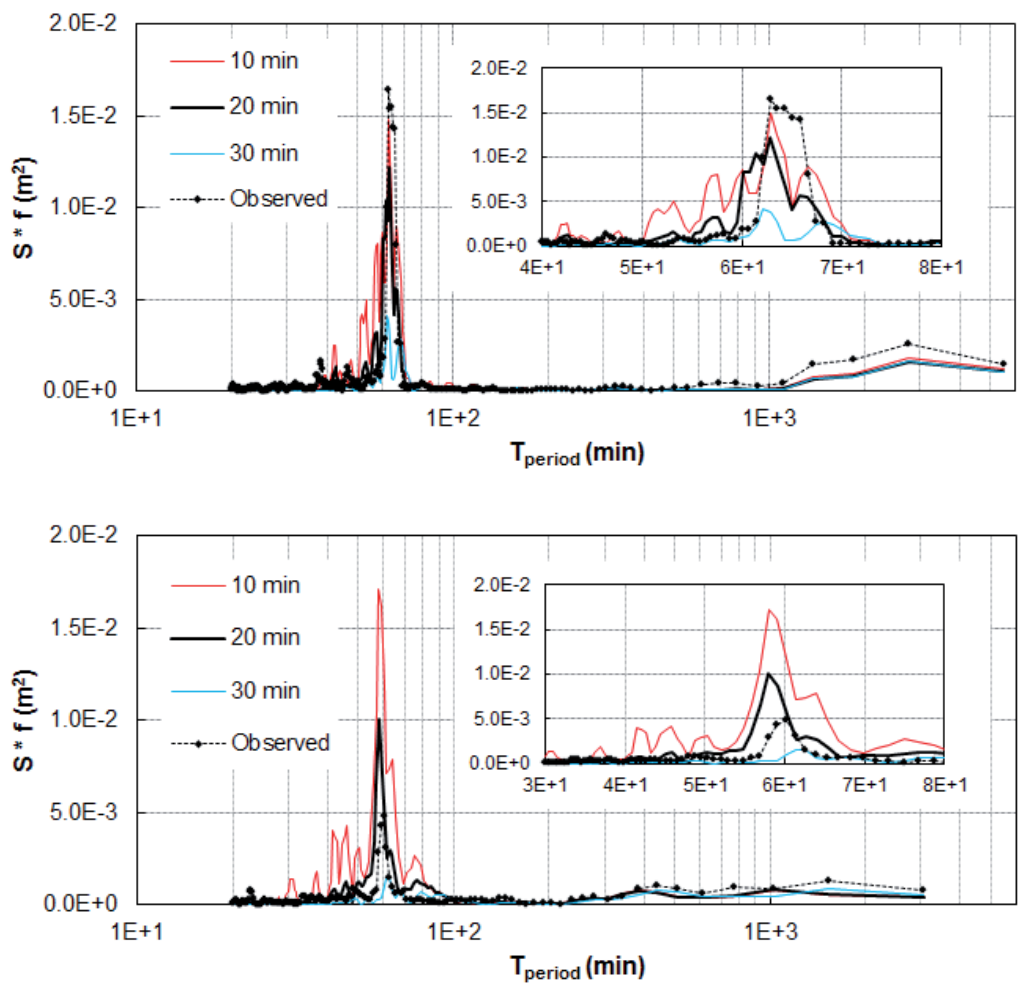

Fig. 12 Frequency-weighted energy spectra calculated from observed and simulated water level time series at gauge WL2. Different lines correspond to different temporal resolution of wind forcing. Top panel: October 2009; bottom panel: March 2009. 

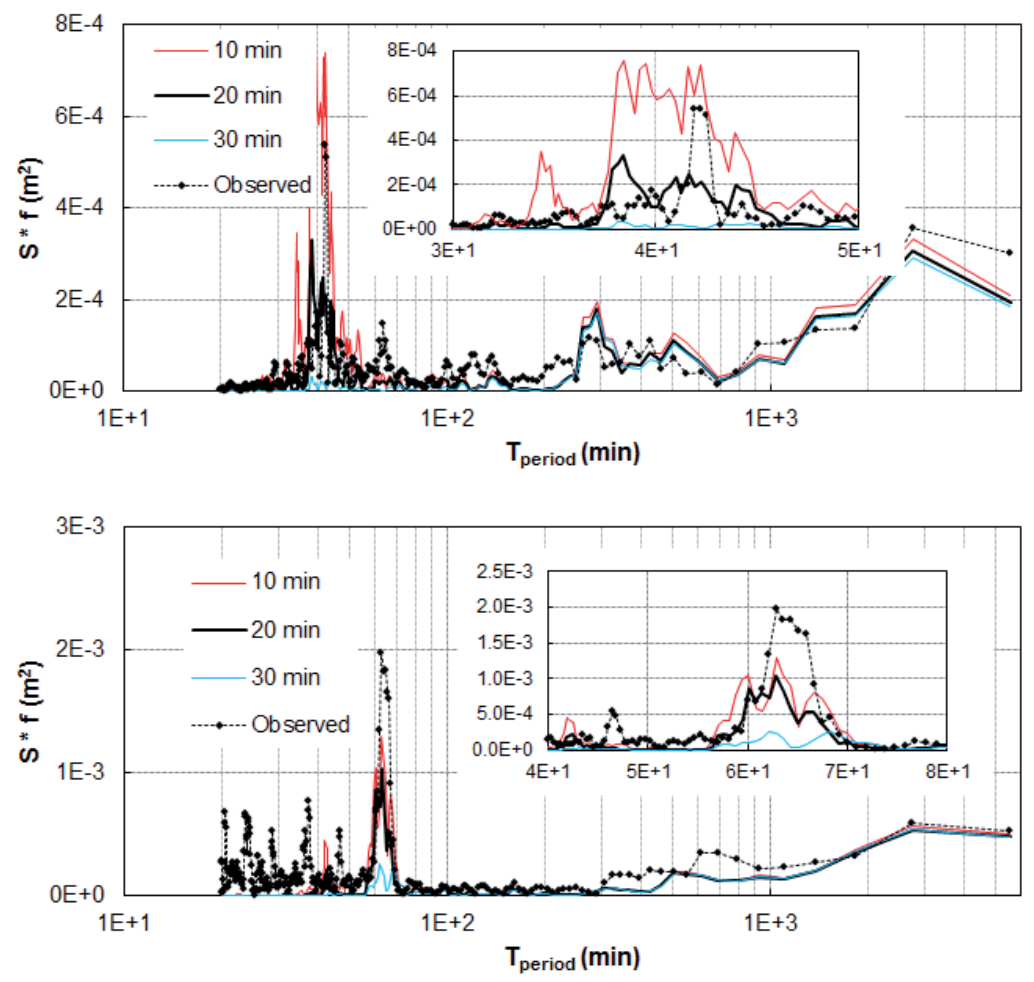

Fig. 13 Frequency-weighted energy spectra calculated from observed and simulated water level time series during October 2009 at gauges WL4 (top panel) and WL3 (bottom panel).

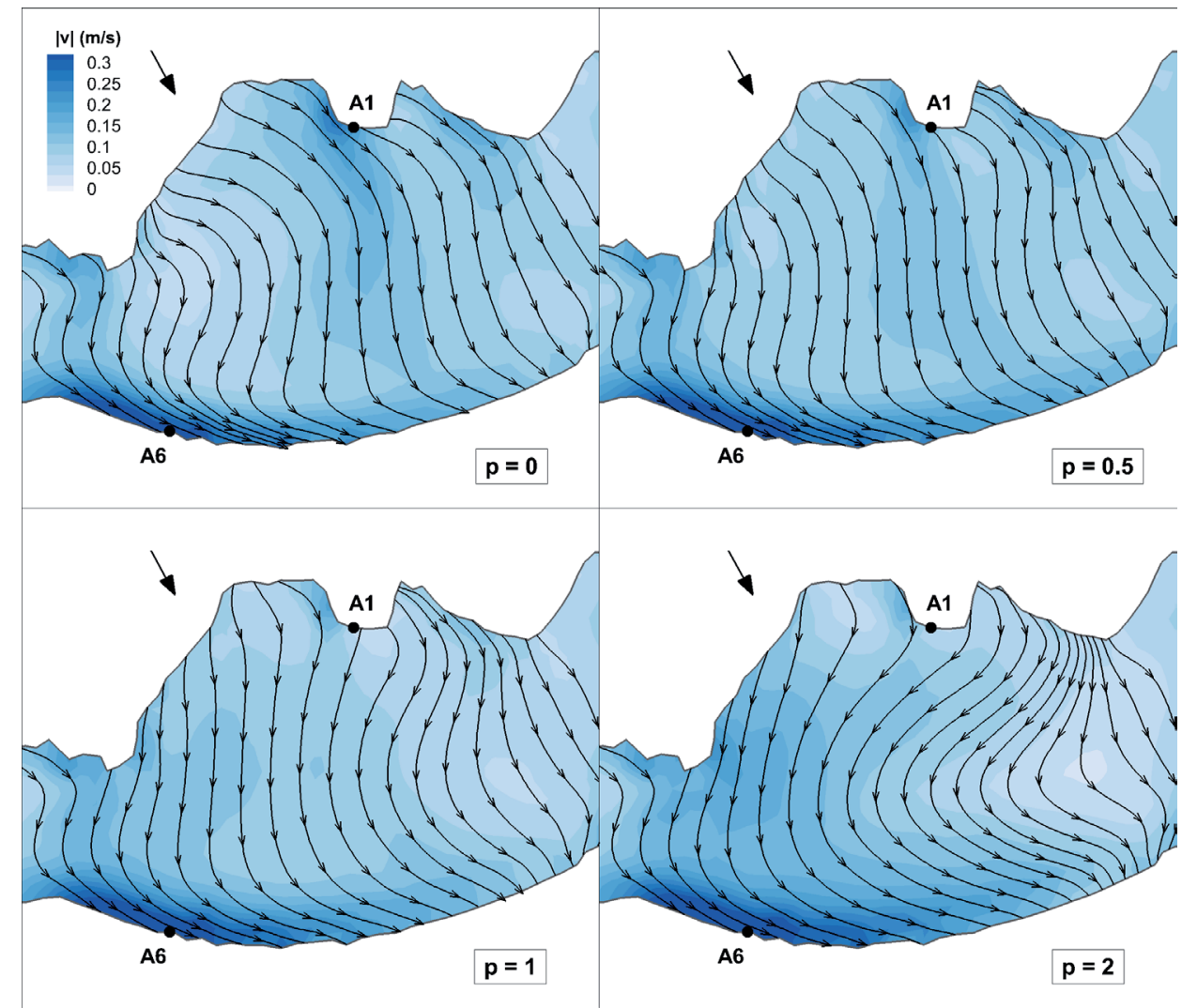

Fig. 14 Simulated near-surface streamlines and velocity magnitudes based in bay II, averaged for the simulation period in March 2009. 
Until now the hydrodynamic consequences of various wind stress interpolation parameters were studied via the water level fluctuations. But lake currents are known to be sensitive not only to the total wind force but also to the spatial gradients of the wind stress, more specifically to the curl. Finally, to extend the previous sensitivity study, the four unsteady wind stress fields interpolated with different $p$ values (Fig. 7 shows their temporal average) were set as input to the lake model and the simulated near-surface currents were averaged over the whole simulation period. Large differences can be seen between the quadrants, reflecting that the power parameter $p$ of the IDW interpolation has a stark influence stress curl. In consequence, the optimal value of $p$ can be determined with even higher confidence if water current measurements are available. We recall that the adopted power parameter was $p=0.5$.

\section{Conclusions}

Since the most energetic motions of shallow lakes are driven by the wind shear stress, its spatial distribution has a great influence on transport processes. Therefore the wind forcing has to be described accurately in hydrodynamic models. At short fetches a prominent and consistent cause of variability is the change of surface roughness: when airflow arrives from rough land onto a smooth water surface, wind speed and shear stress increase with fetch over the water. Many medium-sized lakes are too small so that a new over-lake equilibrium wind state is never reached for strong storms. This process leads to the development of an internal boundary-layer within the ABL and consequently to an uneven wind stress field. In practice, available routine weather observations provide wind time series averaged on a time scale between 5 minutes and a few hours. Around many larger lakes with environmental or economic importance, a network of weather stations provides continuous information about the variability of the wind field. In this paper a simple spatially varying wind stress interpolation method is presented to make the most of this data. The applied interpolation scheme uses the well-known inverse-distance weighting in conjunction with an algebraic IBL model that captures the increment of wind stress along fetch.

A key virtue of this wind interpolation scheme is that its input requires widely available wind time series from weather service anemometers. All reliable, unobstructed anemometers should be included from the vicinity, as far as they represent the wind climate of the lake. Anemometers can be sited on the windward or the leeward shore, or even over the lake; the IBL model takes care of the spatial transformation. The IBL-aware interpolation scheme has been cross-validated with wind measurements at multiple locations around Lake Balaton. Further validation was provided by the $3 \mathrm{D}$ hydrodynamic lake model showing that the calculated wind forcing field is accurate enough to reproduce water level fluctuations at several gauges.
The key conclusions of this analysis are summarised in the following.

The wind model requires two roughness parameters, the Charnock parameter $(\alpha)$ for water and the roughness height of the surrounding land $\left(z_{0}^{l}\right)$. Several parameter combinations exist that yields similar longitudinal wind speed profiles but result in significantly different wind shear stresses. Thus, the IBL model cannot be calibrated unambiguously if only wind speed measurements are available, even at several locations along the fetch.

To be well posed, it would be straightforward to request high-resolution turbulence stress observations for the calibration. This is however not provided with routine weather data. Instead, to estimate the wind force transmitted to the lake, a hydrodynamic model has been involved and provided sufficient additional information for a successful calibration.

Compared to a direct interpolation of wind data without an IBL model, the presented interpolation scheme improves not only the estimation of the total wind force but also that of the wind stress curl. In this paper, we restricted ourselves to demonstrating that the modelled average surface currents are quite sensitive to the IDW interpolation parameter $p$. However, verifying the curl of the wind stress field would require comparison of water currents from targeted field surveys, which we did not attempt in this work.

The averaging interval of the wind forcing also plays a key role in the prediction of lake motions. Long averaging intervals or low time resolution leads to a loss of kinetic energy in the unresolved temporal scales of the wind. The sensitivity analysis showed that in order to predict the crosswise lake seiche components with a period of app. 60 minutes, the temporal wind averaging interval has to be shorter than 30 minutes. In the particular case of Lake Balaton, a 20-minute wind averaging can be suggested.

\section{Acknowledgements}

We thank to the developers group of Marine Ecosystem Dynamics Modeling Laboratory (MEDML) at the School for Marine Science and Technology, University of MassachusettsDartmouth for providing the source code of FVCOM. We wish to acknowledge the contribution of Lake Balaton Development Council to provide access to the database of the Lake Balaton Storm Warning System.

\section{References}

[1] Laval, B., Imberger, J., Hodges, B. R., Stocker, R. "Modeling circulation in lakes: Spatial and temporal variations." Limnology and Oceanography. 48(3), pp. 983-994. 2003. DOI: 10.4319/1o.2003.48.3.0983

[2] Rubbert, S., Köngeter, J. "Measurements and three-dimensional simulations of flow in a shallow reservoir subject to small-scale wind field inhomogeneities induced by sheltering." Aquatic Sciences. 67(1), pp. 104-121. 2005. DOI: 10.1007/s00027-004-0719-4 
[3] Podsetchine, V., Schernewski, G. "The influence of spatial wind inhomogeneity on flow patterns in a small lake." Water Research. 33(15), pp. 3348-3356. 1999. DOI: 10.1016/S0043-1354(99)00035-4

[4] Józsa, J. "Sekély tavak szél keltette cirkulációs áramlásai." (Wind-induced circulations in shallow lakes.) Doctoral dissertation to the Hungarian Academy of Sciences, 2001. (in Hungarian)

[5] Rueda, F., Vidal, J., Schladow, G. "Modeling the effect of size reduction on the stratification of a large wind-driven lake using an uncertaintybased approach." Water Resources Research. 45(3), 2009. DOI: 10.1029/2008WR006988

[6] Finardi, S., Morselli, M. G., Jeannet, P. "Wind flow models over complex terrain for dispersion calculation." Cost Action 710, Pre-processing of Meteorological Data for Dispersion Models, Report of Working Group 4, 1997.

[7] Beletsky, D., Schwab, D. J., Roebber, P. J., McCormick, M. J., Miller, G. S., Saylor, J. H. "Modeling wind-driven circulation during the March 1998 sediment resuspension event in Lake Michigan." Journal of Geophysical Research: Oceans. 108(C2), p. 3038. 2003.

DOI: 10.1029/2001JC001159

[8] Scheuermann, W., Schmidt, F., Krass, C. "Modellierung des Windfeldes als Antriebskraft für die interne Strömung im Bodensee." Wasserwitschaft. 10, pp. 22-25. 2008. (in German)

[9] Hobbs, S. E. "Atmospheric boundary layer flows: Their structure and measurement: Kaimal, J. C., Finnigan, J. J., 1994, 289 pp. Oxford University Press, New York, £50 hb, ISBN 0-19506239-6." Journal of Atmospheric and Terrestrial Physics. 57(11), p. 1357. 1995.

DOI: 10.1016/0021-9169(95)90002-0

[10] Foken, T. "Micrometeorology." Springer-Verlag Berlin, 2008.

[11] Józsa, J. "On the internal boundary layer related wind stress curl and its role in generating shallow lake circulations." Journal of Hydrology and Hydromechanics. 62(1), pp. 16-23. 2014. DOI: 10.2478/johh-2014-0004

[12] Józsa, J., Milici, B., Napoli, E. "Numerical simulation of internal boundary-layer development and comparison with atmospheric data." Boundary-Layer Meteorology. 123(1), pp. 159-175. 2007. DOI: $10.1007 / \mathrm{s} 10546-006-9134-9$

[13] Scott, D., Schwab, D., Zuzek, P., Padala, C. "Hindcasting wave conditions on the North American Great Lakes." In: 8th International Workshop on Wave Hindcasting and Forecasting, North Shore, Hawaii, Nov. 14-19, 2004.

[14] Cook, C. B., Orlob, G. T., Huston, D. W. "Simulation of wind-driven circulation in the Salton Sea: implications for indigenous ecosystems." $\mathrm{Hy}$ drobiologia. 473(1), pp. 59-75. 2002. DOI: 10.1023/A:1016517331869

[15] Barnes, S. L. "A Technique for Maximizing Details in Numerical Weather Map Analysis." Journal of Applied Meteorology. 3(4), pp. 396-409. 1964. DOI: 10.1175/1520-0450(1964)003<0396:ATFMDI>2.0.CO;2

[16] Vickers, D., Mahrt, L. "Fetch limited drag coefficients." Boundary-Layer Meteorology. 85(1), pp. 53-79. 1997. DOI: 10.1023/a:1000472623187

[17] Verkaik, J. W. "A method for geographical interpolation of wind speed over hetergenous terrain." De Bilt, 2001.
[18] Taylor, P. A., Lee, R. J. "Simple guidelines for estimating wind speed variations due to small scale topographic features." Climatological Bulletin. 18(2), pp. 3-32. 1984.

[19] Charnock, H. "Wind stress on a water surface." Quarterly Journal of the Royal Meteorological Society. 81(350), pp. 639-640. 1955.

DOI: $10.1002 /$ qj.49708135027

[20] Drennan, W. M., Graber, H. C., Hauser, D., Quentin, C. "On the wave age dependence of wind stress over pure wind seas." Journal of Geophysical Research: Oceans. 108(C3), pp. 1-13. 2003. DOI: 10.1029/2000JC000715

[21] Savelyev, S. A., Taylor, P. A. "Internal boundary layers: I. Height formulae for neutral and diabatic flows." Boundary-Layer Meteorology. 115(1), pp. 1-25. 2005. DOI: 10.1007/s10546-004-2122-Z

[22] Elliott, W. P. "The growth of the atmospheric internal boundary layer." Eos, Transactions American Geophysical Union. 39(6), pp. 1048-1054. 1958. DOI: 10.1029/TR039i006p01048

[23] Kiss, M., Józsa, J. "Measurement-based hydrodynamic characterisation of reed - open water interface zones in shallow lake environment." Periodica Polytechnica Civil Engineering. 58(3), pp. 229-241. 2014. DOI: 10.3311/PPci.7569

[24] Wieringa, J., Davenport, A. G., Grimmond, C. S. B., Oke, T. R. "New Revision of Davenport Roughness Classification." In: 3rd European and African Conference on Wind Engineering, Eindhoven, Netherlands, June 2001, pp. 1-8.

[25] Chen, C., Liu, H., Beardsley, R. C. "An Unstructured Grid, Finite-Volume, Three-Dimensional, Primitive Equations Ocean Model: Application to Coastal Ocean and Estuaries." Journal of Atmospheric and Oceanic. 20(1), pp. 159-186. 2003.

DOI: 10.1175/1520-0426(2003)020<0159:AUGFVT>2.0.CO;2

[26] Huang, H., Chen, C., Cowles, G. W., Winant, C. D., Beardsley, R. C., Hedstrom, K. S., Haidvogel, D. B. "FVCOM validation experiments: Comparisons with ROMS for three idealized barotropic test problems." Journal of Geophysical Research: Oceans. 113(C7), 2008. DOI: 10.1029/2007JC004557

[27] Chen, C., Huang, H., Beardsley, R. C., Liu, H., Xu, Q., and Cowles, G. "A finite volume numerical approach for coastal ocean circulation studies: Comparisons with finite difference models." Journal of Geophysical Research: Oceans. 112(C3), 2007. DOI: 10.1029/2006JC003485

[28] Anderson, E., Schwab, D., Lang, G. "Real-Time Hydraulic and Hydrodynamic Model of the St. Clair River, Lake St. Clair, Detroit River System." Journal of Hydraulic Engineering. 136(8), pp. 507-518. 2010. DOI: 10.1061/(ASCE)HY.1943-7900.0000203

[29] Józsa, J., Bárdossy, A., Krámer, T. "Handling time scale issues in wind input for improved modelling of lake hydrodynamics." In: Hydroinformatics 2000: Proceedings of the 4th International Conference. 2000, pp. 23-27. 